\title{
PERAN GANDA IBU RUMAH TANGGA DALAM MENINGKATKAN KESEJAHTERAAN EKONOMI KELUARGA
}

\author{
Widya Parimita ${ }^{1}$, Munawaroh $^{2}$, Intan Maulida Rizaldy ${ }^{3}$ \\ 1,2,3Program Studi Administrasi Perkantoran, Fakultas Ekonomi, \\ Universitas Negeri Jakarta \\ ${ }^{1}$ widya_parimita@unj.ac.id, ${ }^{2}$ moena0375@gmail.com, ${ }^{3}$ rizaldyintan@gmail.com
}

\begin{abstract}
Many women today have two roles at the same time, the domestic role in charge of taking care of the household and the role of the public who are in charge outside the home or work to meet the needs of family life. The dual role as a woman in this case must be handled wisely and must maximize her duties in both aspects. The partners of this program are representatives of education personnel of The State University of Jakarta with a female gender. The purpose of this devotion is for women to have an overview and input about online business and to invite partners to become independent women through dual roles as housewives and maximize their ability to help the family economy in online business activities as career women. Classic methods with lecture and discussion approaches are applied in this activity. The end result achieved from this activity is increased motivation and knowledge of partners to double role, namely becoming a housewife and becoming a career woman through online business activities.
\end{abstract}

Keywords: dual role of housewife; family economy; online business

\begin{abstract}
Abstrak
Perempuan masa kini banyak yang memiliki dua peran sekaligus, yakni peran domestik yang bertugas mengurus rumah tangga dan peran publik yang bertugas di luar rumah atau bekerja untuk memenuhi kebutuhan hidup keluarga. Peran ganda sebagai perempuan dalam hal ini harus disikapi dengan bijak serta harus memaksimalkan tugasnya dikedua aspek tersebut. Mitra program ini adalah perwakilan tenaga kependidikan Universitas Negeri Jakarta berjenis kelamin perempuan. Tujuan dari pengabdian ini agar wanita mempunyai gambaran dan masukan tentang bisnis online serta untuk mengajak mitra menjadi wanita yang mandiri melalui peran ganda sebagai ibu rumah tangga dan memaksimalkan kemampuan yang dimilikinya untuk membantu perekonomian keluarga dalam kegiatan bisnis online sebagai wanita karir. Metode klasikal dengan pendekatan ceramah dan diskusi diterapkan dalam kegiatan ini. Hasil akhir yang dicapai dari kegiatan ini adalah meningkatnya motivasi dan pengetahuan mitra untuk berperan ganda yaitu menjadi ibu rumah tangga serta menjadi wanita karir melalui kegiatan bisnis online.
\end{abstract}

Kata Kunci: peran ganda ibu rumah tangga; ekonomi keluarga; bisnis online

\section{PENDAHULUAN}

Era sekarang ini, dunia Teknologi Informasi dan Komunikasi (TIK) sudah berkembang sangat pesat. Salah satu penyebabnya adalah pandemic covid-19 yang melanda seluruh dunia termasuk Indonesia, tentu saja hal ini memunculkan pola dan kebiasaan hidup baru bagi kalangan masyarakat termasuk dalam hal penggunaan teknologi. Dalam data Internet World Stats (2021) menyatakan bahwa di Indonesia sendiri, pengguna internet mencapai 196 juta di tahun 2020. 


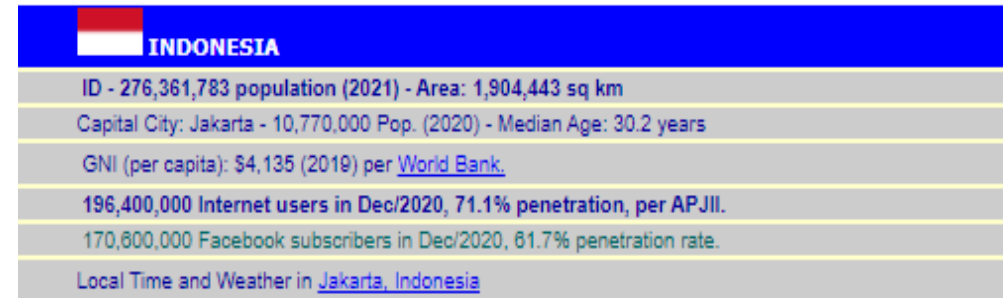

Gambar 1. Penggunaan Internet di Indonesia

Pemberdayaan Ibu Rumah Tangga merupakan langkah dalam meningkatkan kemampuan dan potensi yang dimiliki, sehingga Ibu Rumah Tangga dapat mewujudukan jati diri, harkat serta martabatnya. Kesejahteraan dalam keluarga pun tidak tergantung pada besar kecil penghasilan suami tetapi bagaimana seorang istri dapat mengelola keuangan dengan baik. Untuk menutupi kekurangan yang ada maka istri dapat membantu meringankan beban suami dengan menambah penghasilan bersama, salah satu caraya adalah bisnis online. (Setiawati \& Rozinah, 2020).

Bekerja merupakan ekspresi untuk mengaktulisasikan diri secara fisik dan psikologis untuk bersosialisasi dengan lingkungan, disamping mendapat reward berupa gaji sehingga dapat mandiri dalam berekonomi. Selain itu dengan bekerja wanita yang berperan ganda mampu mengatur work-life balance sehingga dapat tercapai kepuasan dan kesejahteraan dalam hidup (Budaya et al, 2020).

Dalam pemanfaatan TIK, besar peluang bagi perempuan untuk memaksimalkan potensi yang dimiliki dan meningkatkan kesejahteraan ekonomi keluarga. Peluang usaha melalui digital dinilai sangat potensial. Data menunjukkan bahwa sepanjang pandemi transaksi ritel online meningkat secara signifikan dari $4,7 \%$ menjadi
$28,9 \%$ sementara transaksi offline turun dari 52,3\% menjadi 28,9\% (MarkPlus). Oleh karena itu, akses dan kesempatan bagi perempuan terhadap digital harus dibuka lebar (Publikasi dan Media, 2020).

Pada tahun 2018 tercatat data bahwa usaha yang dilakukan oleh perempuan mencapai 57,83 juta dengan lebih dari $60 \%$ dikelola oleh perempuan (jumlah pelaku usaha mmencapai 37 juta). Bidang yang paling banyak dilakukan adalah 41,69\% bergerak dibidang kuliner, $18.15 \%$ bergerak dibidang fashion dan 15,70\% bergerak dibidang kriya (Kumparan, 2018).

Berdasakan pemaparan masalah diatas, terlihat jelas bahwa dibutuhkannya peran ganda ibu rumah tangga untuk berkontribusi dalam meningkatkan kesejahteraan keluarga. Salah satu cara yg dapat diterapkan adalah dengan berbisnis.

Seperti yang telah dipaparkan sebelumnya, bisnis online sudah dikuasai oleh Ibu Rumah Tangga. Menghadapi kondisi tersebut, penulis tertarik untuk melakukan pelatihan dan pengabdian kepada masyarakat untuk meningkatkan motivasi Ibu Rumah Tangga yaitu Seminar Peran Ganda Ibu Rumah Tangga dalam Meningkatkan Kesejahteraan Ekonomi Keluarga untuk meningkatkan kesejahteraan keluarga melalui kegiatan bisnis online. 


\section{METODE PELAKSANAAN}

Metode pelatihan yang digunakan adalah metode klasikal dengan pendekatan ceramah dan diskusi dengan maksud agar materi dapat diterima oleh peserta dengan baik. Jenis aktifitas yang akan dilakukan dalam rangkaian kegiatan ini meliputi:

a. Identifikasi dan Penetapan Target Peserta

Peserta dalam program pengabdian masyarakat ini adalah perwakilan tenaga kependidikan Universitas Negeri Jakarta (UNJ), berjenis kelamin perempuan dan termasuk dalam klasifikasi Golongan II di masing-masing fakultas yang ada di UNJ. Adapun fakultas yang dimaksud antara lain: FE, FIP, FMIPA, FIS, FT, FIK, FBS, FPP, Pasca Sarjana.

b. Pembinaan

Sosialisasi perkembangan bisnis online, menumbuhkan motivasi bisnis pada diri perempuan, membuat strategi penerapan peran ganda perempuan dalam hal parenting dan bisnis. Setelah materi selesai dipaparkan, dilanjutkan dengan diskusi berupa tanya jawab antara pemateri dengan peserta. Diskusi dilakukan agar peserta lebih memahami materi yang telah disampaikan.

c. Pelatihan

Pelatihan berupa tutorial dan pendampingan praktek kepada mitra agar dapat membuat dan mengoperasikan toko online dalam kegiatan usaha. Adapun aplikasi yang akan dipraktekkan yaitu Instagram.

\section{d. Bimbingan/Konsultasi}

Setelah tahapan pelatihan, tahapan selanjutnya adalah praktik yang dilakukan secara langsung oleh peserta/mitra serta disediakan sarana untuk berkonsultasi secara online.

e. Evaluasi

Dilakukan untuk mengetahui hasil dan progress dari pelaksanaan program yang telah direncanakan menggunakan cara membandingkan kondisi kedua mitra sebelum program dilaksanakan dan kondisi mitra setelah program dilaksanakan.

\section{HASIL DAN PEMBAHASAN}

Hasil dan pembahasan berisi hasilhasil temuan pengabdian Masyarakat dan pembahasannya. Tuliskan temuantemuan yang diperoleh dari hasil-hasil penelitian yang telah dilakukan dan harus ditunjang oleh data-data yang memadai. Hasil-hasil pengabdian Masyarakat dan temuan harus bisa menjawab pertanyaan atau hipotesis pengabdian Masyarakat di bagian pendahuluan.

Teknologi pada mulanya mempermudah pekerjaan manusia, seiring waktu beralih fungsi untuk memperlancar bisnis untuk mendapatkan income yang lebih besar. Pada dunia bisnis bermunculkan istilah e-bussiines, e-commerce, dan marketplace serta lainnya.

Dengan adanya teknologi digital dalam bisnis, pemasaran produk lebih efektif dan efisien. Hanya dengan mengakses melalui smartphone serta media sosial pelaku bisnis mampu bertransaksi, negosiasi serta 
berkomunikasi untuk memperluas bisnis yang dijalankan.

Motivasi bisnis pada diri perempuan dapat bertumbuh seiring dengan kebutuhan hidup. Semakin lama, biaya hidup pun semakin meningkat. Untuk menyikapi peningkatan biaya hidup pun seseorang harus memiliki penghasilan yang relative besar guna menutupi biaya tersebut.

Salah satu cara menutupi biaya hidup tersebut dengan menjalankan bisnis online. Untuk seorang ibu rumah tangga yang memutuskan menjalankan bisnis online maka sudah siap menanggung tekanan dalam pekerjaan serta keluarga dan resiko lainnya.

Maka beberapa permasalahan yang dirumuskan oleh Peneliti adalah:

a. Kurangnya motivasi perempuan dalam menjalankan bisnis online sehingga tidak memanfaatkan kondisi pandemi covid-19 sebagai peluang untuk berwirausaha.

b. Penggunaan teknologi yang belum maksimal sehingga saat memasarkan produk yang dipasarkan kurang menarik perhatian pelanggan.

Menurut Puspitawati et al (2019) kesejahteraan keluarga dapat terlihat seberapa banyak rasa kebahagiaan yang dialami oleh keluarga Keluarga dapat dikatakan sejahtera jika keadaan keluarganya makmur, sehat serta damai. Dapat dilihat pada aspek fisik, pendapatan, kesehatan, pendidikan dan sosial ekonomi (Marlina Telaumbanua \& Nugraheni, 2018).

Tingkat kesejahteraan keluarga secara langsung dipengaruhi oleh pendapatan. Pendapatan dalam keluarga dilihat sebagai indikator utama untuk memenuhi kebutuhan sehari-hari (Rafidah, 2019). Pemberdayaan perempuan berperan penting dalam keberlangsungan hidup keluarga, baik yang berkaitan dengan pembinaan moral anak maupun pemenuhan kebutuhan ekonomi keluarga sebagai salah satu pilar utama kesejahteraan keluarga (Zain \& Isa, 2020).

Dimensi kesejahteraan keluarga sangat luas dan kompleks. Dapar diukur dengan yang terlihat (fisik dan kesehatan) dan tidak dapat dilihat (spiritual) (Faruq \& Esa, 2018). Beberapa istilah yang digunakan untuk menganalisis tingkat kesejahteraan keluarga, sebagai berikut :

a. Kesejahteraan ekonomi seperti pendapatan perbulan, nilai asset.

b. Kesejahteraan sosial seperti tingkat pendidikan baik formal maupun informal

c. Kesejahteraan fisik seperti status gizi, kesehatan, tingkat moralitas dan morbiditas.

Safrizal et al, (2020) menyatakan bahwa peran ganda ibu rumah tangga dapat terbagi menjadi dua yaitu peran tradisional atau domestik meliputi peran sebagai istri serta ibu dan peran transisi meliputi peran sebagai pekerja

Peran ganda dapat diartikan sebagai kepemilikan dua peran dalam waktu yang bersamaan. Dalam konteks ini peran ganda yang dimaksud adalah peran wanita sebagai wanita dan karir. Karir diartikan sebagai ambisi seseorang dalam menekuni suatu bidang (Ginting, 2019). 
Lukes (2017) menyatakan bahwa peran ibu rumah tangga dalam keluarga adalah memenuhi kebutuhan hidup secara lengkap, saat seorang istri melakukan pekerjaan maka istri berkontribusi membantu memperbaiki kondisi keluarga secara ekonomi.

Peran wanita sebagai seorang ibu atau istri yang bertugas mendampingi suami dan anak dalam situasi apapun dengan penuh kasih sayang, cinta, kesetiaan dan loyalitas. Seorang wanita yang sudah menikah dan menjadi ibu terkadang memiliki dua pilihan yaitu sebagai ibu sepenuhnya mengurusi rumah tangga atau membantu perekonomian keluarga dengan bekerja (Empati et al, 2019).

Fenomena yang terjadi di masyarakat menunjukan bahwa semakin banyak perempuan yang membantu suami untuk mencari penghasilan tambahan, selain didorong oleh kebutuhan ekonomi keluarga tetapi juga karena keinginan untuk mengekspresikan diri dalam keluarga dan masyarakat (Halidin, 2019).

Internet berubah dan terbentuk bergantung pada pengguna. Dari cyber cafe sampai bisnis. Pemasaran adalah hal terpenting dalam berbisnis. Penggunaan teknologi informasi sangat mempengaruhi bisnis online dan dianggap sebagai trendsetter serta memudahkan dalam pemasaran untuk menarik konsumen (Soegoto \& Akbar, 2018). Menurut Tarhini et al (2018) ada
3 kontruksi sebagai penentu utama perilaku pengguna teknologi, yaitu harapan kinerja, harapan usaha dan pengaruh sosial.

Bisnis tradisional berubah karena adanya evolusi teknologi Realisasi pemecahan masalah pada kegiatan pengabdian masyarakat ini dilakukan pada hari Rabu, 02 September 2020 dengan mengadakan kegiatan berupa seminar pemaparan, praktik, tanya jawab dan diskusi mengenai hal-hal sebagai berikut:

1. Kiat-kiat memulai usaha dan menjalankan usaha

2. Penjelasan tentang perjalanan dalam usaha narasumber

3. Penjelasan dan praktik mengenai digital marketing

Pemaparan materi disampaikan oleh tiga pelaku bisnis yaitu Lolytha sebagai pelaku usaha Lolytha Apparel, Sekar sebagai pelaku usaha Printilan Rumah, dan Sarah sebagai pelaku usaha Jamoe Iboemadam. Kemudian pemaparan materi digital marketing disampaikan oleh Shandy Aditya BIB., MPBS. Pada paparan seminar tersebut, dijelaskannya mengenai konsep wirausaha sebagai berikut. Materi ini membahas tentang wirausaha. Pemateri menjelaskan tentang awal memulai usaha tersebut,, kiat apa saja agar senang dalam menjalani usaha tersebut hal ini bisa dengan hal-hal yang kita sukai terlebih dahulu, memanfaatkan peluang yang ada dimasyarakat dengan melihat yang sedang ramai dipasar. 


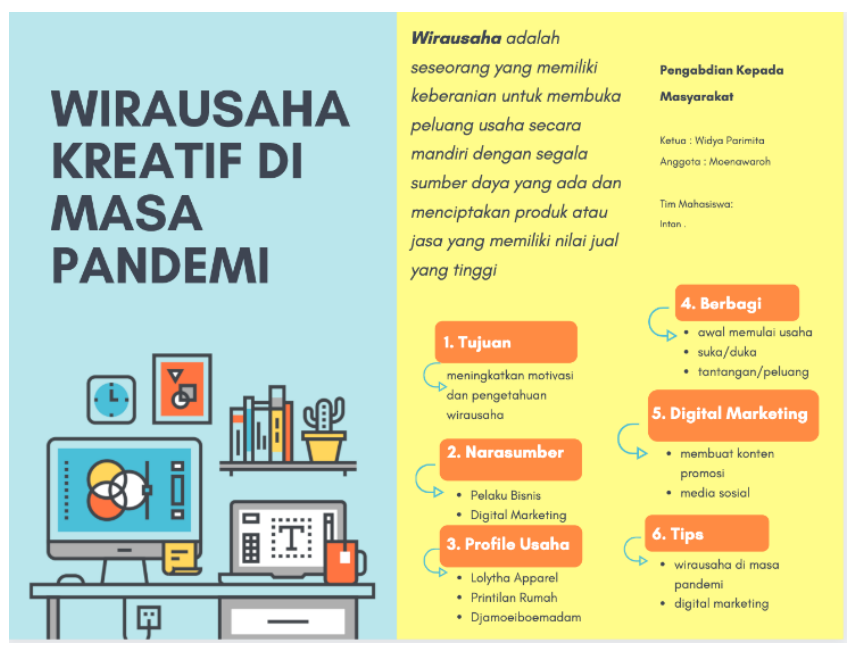

Gambar 2. Konsep Wirausaha

Materi ini membahas tentang wirausaha. Pemateri menjelaskan tentang awal memulai usaha tersebut, kiat apa saja agar senang dalam menjalani usaha tersebut hal ini bisa dengan hal-hal yang kita sukai terlebih dahulu, memanfaatkan peluang yang ada dimasyarakat dengan melihat yang sedang ramai dipasar.

Kemudian, penjelasan beserta praktik tentang digital marketing yaitu dengan memanfaatkan gadget seperti handphone untuk keperluan usaha, cara menarik minat konsumen dan pengambilan gambar yang menarik.
Pada akhir acara seminar ini, dijelaskan motivasi dalam menjalankan usaha untuk para ibu rumah tangga serta manfaat seminar pengabdian masyarakat tersebut. Dilanjutkan dengan sesi foto bersama dengan seluruh peserta acara seminar tersebut.

Hasil kesimpulan kegiatan dapat dilihat dari kuesioner yang dilakukan setelah agenda berlangsung, diperoleh hasil yang menunjukan 55 peserta (95\%) menyatakan bahwa penyampaian materi pelatihan membuat peserta menjadi termotivasi untuk membuka usaha serta memanfaatkan digital marketing .

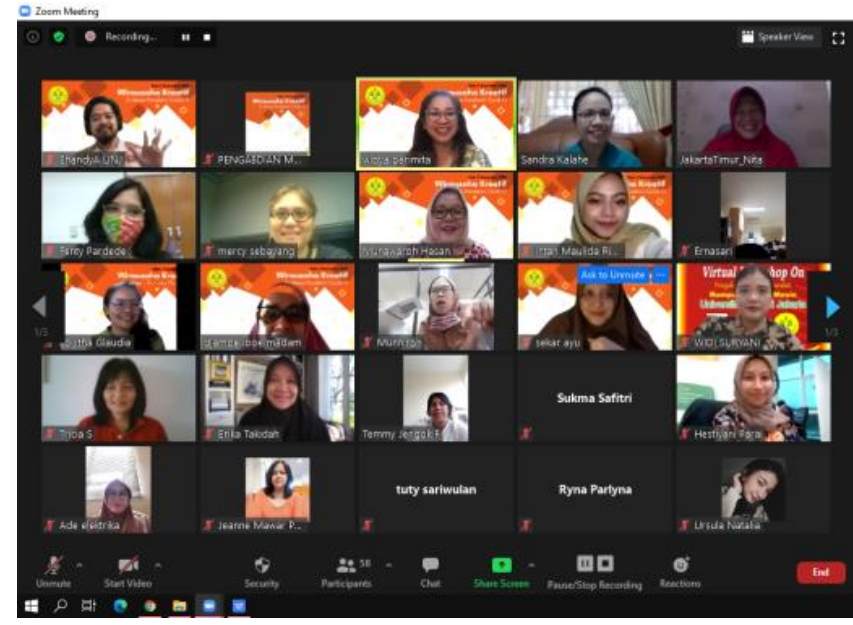

Gambar 3. Foto Bersama 


\section{PENUTUP}

Kegiatan seminar pengabdian kepada masyarakat yang telah dilakukan, dapat disimpulkan bahwa peserta merasa sangat senang dan puas dengan paparan materi yang diberikan. Para peserta dari kalangan Ibu Rumah Tangga mendapatkan pengetahuan dan motivasi baru dalam langkah memulai usaha atau menjalankan usaha tersebut agar lebih siap bersaing ditengah pasar yang ada. Kegiatan penyampaian materi dilakukan dengan santai dan interaktif membuat seminar tersebut berjalan dengan baik dari awal acara hingga akhir acara. Berdasarkan evaluasi yang ada dapat diajukan saran bahwa perlu dilakukan kegiatan coaching dan pendampingan dalam memulai dan menjalankan usaha.

\section{DAFTAR PUSTAKA}

Budaya, D. S., Bagus, D., Satata, M., Malang, U. M., Shusantie, M. A., \& Malang, U. N. (2020). Peran Ibu Dalam Berkarir Dan Kehidupan Berkeluarga. 22(2), 165-170.

Empati, J., Anwar, D. P., \& Fauziah, N. (2019). Hubungan Antara Kesejahteraan Psikologis Dengan Konflik Peran Ganda Pada Wanita Yang Bekerja Sebagai Polisi Di Polrestabes Semarang. Empati, 8(1), 105-110.

Etminani-Ghasrodashti, R., \& Hamidi, S. (2020). Online shopping as a substitute or complement to instore shopping trips in Iran? Cities, 103(May), 102768. https://doi.org/10.1016/j.cities.202 0.102768

Faruq, U. Al, \& Esa, P. P. N. (2018). Peran Ganda Ibu Rumah Tangga
Pada Sektor Ekonomi Informal Untuk Meningkatkan Family Welfare: Studi Pada Ibu Rumah Tangga Dikelurahan Serua Indah Kecamatan Ciputat Yang Bekerja Sebagai Pedagang Busana. Pekobis Jurnal Pendidikan Ekonomi Dan Bisnis, 1(V), 1-16.

Fu, H., Manogaran, G., Wu, K., Cao, M., Jiang, S., \& Yang, A. (2020). Intelligent decision-making of online shopping behavior based on internet of things. International Journal of Information Management, $\quad 50$ (November 2018), 515-525. https://doi.org/10.1016/j.ijinfomgt .2019 .03 .010

Ginting, P. A. (2019). Implementasi Teori Maslow dan Peran Ganda Pekerja Wanita K3L Universitas Padajajaran. Focus: Jurnal Pekerjaan Sosial, 1(3), 220. https://doi.org/10.24198/focus.v1i 3.20498

Halidin, A. (2019). Dual Role Is Adjusting The Conflict of Employees Women In Pinrang Regency Office. Maret 2019 Journal of Research and Multidisciplinary, 2(1), 84-93. https://doi.org/https://doi.org/10.5 281/jrm.v2i1.\%25

Internet World Stats. (2021). https://www.internetworldstats.co $\mathrm{m} /$ asia.htm\#id

Kumparan. (2018). Infografik: 60 Persen UMKM di Indonesia dikelola oleh Perempuan. KumparanSTYLE. https://kumparan.com/kumparanst yle/infografik-60-persen-umkmdi-indonesia-dikelola-olehperempuan- 
1539947445397507929/full

Ladhari, R., Gonthier, J., \& Lajante, M. (2019). Generation Y and online fashion shopping: Orientations and profiles. Journal of Retailing and Consumer Services, 48(January), 113-121.

https://doi.org/10.1016/j.jretconse r.2019.02.003

Lukes, E. (2017). The role of the professional supervisor. $A A O H N$ Journal, 59(2), 57-59. https://doi.org/10.3928/0891016220110126-03

Marlina Telaumbanua, M., \& Nugraheni, M. (2018). Peran Ibu Rumah Tangga Dalam Meningkatkan Kesejahteraan Keluarga. Sosio Informa, 4(2), 418-436.

https://doi.org/10.33007/inf.v4i2.1 474

Publikasi dan Media, K. (2020). Menteri Bintang :

Tingkatkan

Pemberdayaan Ekonomi Perempuan melalui TIK. https://www.kemenpppa.go.id/ind ex.php/page/read/29/2901/menteri -bintang-tingkatkanpemberdayaan-ekonomiperempuan-melalui-tik

Puspitawati, H., Putri, A. C. J., Titipani, A., \& Khasanah, M. N. (2019). Kontribusi Ekonomi Perempuan, Tekanan Ekonomi dan Kesejahteraan Keluarga pada Keluarga Nelayan dan Buruh Tani Bawang Merah. Jurnal Ilmu Keluarga Dan Konsumen, 12(2), 87-99.

https://doi.org/10.24156/jikk.2019 .12 .2 .87

Rafidah. (2019). The Effect of Business Capital, Length of Business anda
Entrepreneurship Attitude to The Income and Welfare of The Family Women of Batik Craftsmen in Danau Teluk Jambi City. Li FalahJurnal Studi Ekonomi Dan Bisnis Islam, 4(2), 139-162.

Safrizal, H. B. A., Eliyana, A., \& Febriyanti, K. L. (2020). The effect of double role conflict (work family conflict) on female worker's performance with work stress as the intervening variable. Systematic Reviews in Pharmacy, 11(10), 418-428. https://doi.org/10.31838/srp.2020. 10.65

Setiawati, E., \& Rozinah, S. (2020). Pemberdayaan Ibu-Ibu Rumah Tangga Dalam Upaya Meningkatkan Ekonomi Keluarga Melalui Pengelolaan Usaha Rumahan di Tangerang Selatan. Aksiologiya: Jurnal Pengabdian Kepada Masyarakat, 4(2), 231240.

https://doi.org/10.30651/aks.v4i2. 2611

Soegoto, E. S., \& Akbar, R. (2018). Effect of the internet in improving business transactions with online market methods. IOP Conference Series: Materials Science and Engineering, 407(1). https://doi.org/10.1088/1757899X/407/1/012051

Tarhini, A., Alalwan, A. A., Al-Qirim, N., Algharabat, R., \& Masa'deh, R. (2018). An Analysis of the Factors Influencing the Adoption of Online Shopping. International Journal of Technology Diffusion, 9(3), 68-87. https://doi.org/10.4018/ijtd.20180 70105 
DOI: https://doi.org/10.21009/sarwahita.182.3

P-ISSN: 0216-7484

E-ISSN: 2597-8926

Zain, K., \& Isa, A. B. D. H. (2020). ( Pkk ) Based on Gender Equality in Nauru Wife in Payunga Village Batudaa Gorontalo District. 7(9), 75-79.

Sarwahita : Jurnal Pengabdian Kepada Masyarakat Vol. 18 No. 2 Tahun 2021 | 145 